\title{
A utopia da constituição do "Mapa" da reforma brasileira
}

\author{
Simone Chandler Frichembruder \\ Nádia Geisa de Souza
}

\section{SciELO Books / SciELO Livros / SciELO Libros}

SILVEIRA, MFA., and SANTOS JUNIOR, HPOS., orgs. Residências terapêuticas: pesquisa e prática nos processos de desinstitucionalização [online]. Campina Grande: EDUEPB, 2011. 320 p. ISBN 97885-7879-063-9. Available from SciELO Books $<\underline{\text { http://books.scielo.org }>\text {. }}$

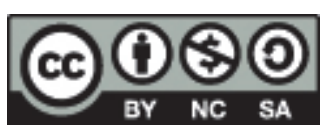

All the contents of this work, except where otherwise noted, is licensed under a Creative Commons Attribution-Non Commercial-ShareAlike 3.0 Unported.

Todo o conteúdo deste trabalho, exceto quando houver ressalva, é publicado sob a licença Creative Commons Atribuição Uso Não Comercial - Partilha nos Mesmos Termos 3.0 Não adaptada.

Todo el contenido de esta obra, excepto donde se indique lo contrario, está bajo licencia de la licencia Creative Commons Reconocimento-NoComercial-CompartirIgual 3.0 Unported. 


\section{A Utopia da Constituição do "Mapa" da Reforma Brasileira}

Simone Chandler Frichembruder

Nádia Geisa de Souza

\section{Introdução}

Em sua obra O Sonho do Cartógrafo, James Cowan (1999) traz as reflexões de Fra Mauro, cartógrafo veneziano do século XVI, cujo trabalho de sua vida era o de construir o mapa perfeito, um mapa que representasse a dimensão da criação. Nesta busca, inúmeros "curiosos", viajantes, exploradores visitavam-no em sua cela, trazendo a cada narrativa um mapa "mais completo". Contudo, acenavam para a impossibilidade de alcançar a perfeição de sua forma, tornando seu contorno cada vez mais extenso e incompreensível.

Movida talvez, pela utopia do cartógrafo na busca pelo "mapa perfeito", fui instigada a construir um "mapa da loucura", dos seus diferentes (des)encontros com a cidade. Semelhante ao cartógrafo veneziano, diante da "figura" que vai se constituindo da Reforma Psiquiátrica no território brasileiro, com contornos cada vez mais extensos e torneados por diferentes percursos em relação à loucura, sinto-me impelida a mapear os (des)caminhos para constitui- 
ção desta outra modalidade de atenção integral em Saúde Mental, denominada Serviços Residenciais Terapêuticos.

Para tanto, percorri as diferentes regiões do país, onde em cinco cidades "colhi" narrativas das experiências que vão configurando cenários da desinstitucionalização no Brasil. Assim, com a intenção de conhecer o cotidiano das relações e da vida dos moradores, nas suas residências, procurei conviver, mesmo que por um curto período, com os moradores, os cuidadores das casas e com os gestores. Tal relação permitiu-me criar "laços" de afeto e de confiança necessários para que pudéssemos conversar sobre as experiências que, ali, foram acontecendo. Dessas "viagens", trouxe, na "bagagem", as narrativas de alguns usuários dos Serviços Residenciais Terapêuticos cadastrados no Programa de Volta para Casa, de seus vizinhos e dos funcionários que os acompanham, como também de gestores dos projetos.

Neste artigo, (a)bordo alguns tracejos da coleta dessas narrativas na busca da "construção" desse mapa, cujo levantamento de dados encontra-se em fase final (FOUCAULT, 2000). A sua escrita está organizada em quatro momentos. Inicialmente, trago maneiras de agir com a "loucura" vivenciadas em diferentes culturas, visando a problematizar a sua pretensa universalidade e os jogos de exclusão que (des)configuram os tracejos do mapa Reforma no País. Em um segundo momento, realizo um traçado dos principais movimentos, Conferências e Dispositivos Legais que delinearam a constituição do Residencial Terapêutico no Brasil. Em um terceiro momento, apresento fragmentos, falas e cenas, de momentos vivenciados com moradores de Residenciais Terapêuticos para tencionar o morar em uma casa atrelada ao Sistema Único de Saúde. Para finalizar, narro momentos de minha passagem por um residencial do sudeste do país, buscando, ao dar "visibilidade" a outras formas de agir e escutar os moradores, chamar a atenção para a possibilidade de outros desenhos na construção do "mapa da Reforma" no Brasil. 


\section{A Nudez admitida na Região Norte e sua Intolerância no Sul do Brasil}

Para iniciarmos esta seção, uma reflexão de Michel Foucault sobre a "loucura" pode nos servir. Segundo ele, em "todas as sociedades há sujeitos que têm comportamentos diferentes dos dos outros escapando as regras comumente definidas" (FOUCAULT, 2002a) em pelo menos quatro domínios de atividades: nas suas relações com o trabalho; nos domínios da sexualidade, família e da reprodução da sociedade; nos domínios da fala e da linguagem e nos domínios dos jogos e das festas (FOUCAULT, 2002a), assumindo o lugar de marginais ao "infringirem" um dos domínios citados.

Tais colocações criam condições para pensarmos que estes "jogos" de exclusão diferenciam-se a partir das possibilidades de tolerância atribuídas a cada um dos domínios, descritos por Foucault, onde "cada cultura tem seu limiar particular" (FOUCAULT, 2000).

Para ampliarmos a discussão acerca da forma como as culturas lidam e configuram a "loucura", tomemos como exemplo a experiência de uma mulher que vive em um município da Região Norte. Luísa, cidadã conhecida naquela cidade, tem por hábito caminhar nua pela cidade. Os moradores, talvez, incomodados pela sua nudez, têm por costume procurar vesti-la. Mas ela, possivelmente, anda sem vestimentas não por falta de "condições financeiras" para adquirir roupas, pois mantém o hábito de andar pela cidade nua, com o rosto pintado, carregando uma bolsa, desprezando as vestimentas presenteadas.

Num dia, ao retornar para minha "morada de passagem" durante a coleta de dados, pude ver, em uma rua movimentada, uma mulher que andava pelas ruas de forma errante com os seios à mostra, vestindo apenas uma bermuda. Diante, daquela cena, o trânsito seguia na velocidade peculiar daquela capital. A mulher não provocava qualquer alteração, seja no movimento dos carros, ou nos 
sons emitidos, e não percebi os gritos peculiares dirigidos a mulheres com os seios à mostra, como talvez fosse acontecer na capital gaúcha. A polícia não participava daquela cena, parecia que ela era invisível aos demais passantes, levando-me a pensar que somente eu me perturbara com a imagem da errância nua daquela mulher na cidade. Na capital gaúcha, Luísa não poderia desfrutar de seu passeio sem roupas, sem receber a reprovação dos condutores de automóveis e a presença da polícia, que possivelmente interromperia a sua caminhada, direcionando-a para o hospício da cidade. A nudez, provavelmente, entraria no domínio da sexualidade, citado por Foucault, produzindo a exclusão de Luísa do espaço da cidade no Sul do país.

As cenas trazendo outros jeitos de lidar e conviver com o comportamento de Luísa, possibilitam-nos pensar que, naquela cidade, a "loucura", ainda, é admitida, reportando-me à familiaridade com a "loucura", na Idade Média, contada por Foucault (1995) ao nos falar sobre a história da loucura. Porém, diferentemente daquele período, hoje, encontram-se, ainda, institucionalizadas 41 pessoas no único hospital psiquiátrico daquele Estado.

Contudo, mesmo que existam diferentes significações em relação à loucura, o que não se distingue é o movimento de exclusão direcionado às pessoas que infringem qualquer um dos domínios mencionados de início, dando contornos ao mapa da exclusão construído durante séculos, através do reconhecimento da loucura em seu habitat. Tal modo de agir move-nos na direção de chamar a atenção para as maneiras como esses domínios vêm operando no processo de reversão do modelo hospitalocêntrico e de "inclusão" dessas pessoas nos espaços da cidade.

Diferentes movimentos precursores da Reforma Psiquiátrica, no cenário Mundial, dos movimentos sociais e Conferências de Saúde Mental realizadas no Brasil, impulsionaram uma gama de encaminhamentos em relação ao processo de "inclusão" e ao destino dos egressos dos hospitais psiquiátricos, com longo período 
de internação, até a instituição da portaria No 106/2000 que criou os Serviços Residenciais Terapêuticos (SRTs) no território brasileiro.

Com o propósito de trazer elementos das condições históricas que tornaram possível "morar" em um Residencial Terapêutico, no Brasil, apresento, a seguir, alguns dos principais movimentos e deliberações das Conferências implicados na instituição dos SRTs.

\section{Movimentos de Desinstitucionalização da Loucura: a Constituição dos Serviços Residenciais Terapêuticos no Brasil (SRTs)}

Para pensarmos sobre a (des)institucionalização dos moradores de hospitais psiquiátricos, parece-nos útil retomar e ter como pano de fundo o conceito de cuidado de Saúde Mental. Segundo Alves e Guljor (2004), o cuidado baseia-se em duas premissas fundadoras: primeiro, a liberdade, segundo, a readequação ao convívio social. Para o autor, o cuidado passa "pela capacidade do sujeito operar suas próprias escolhas, seu potencial de estabelecer suas próprias normatizações pautadas em sua história e de forma singularizada" (ALVES; GULJOR, 2004). Salientam, também, a necessidade de contrapor o isolamento relegado à loucura, por meio de intervenções que catalisem a readequação dessas pessoas ao convívio social.

Os primeiros movimentos em oposição ao isolamento ocorreram, no Brasil, na década de setenta, fomentados por uma diversidade de questionamentos em relação à situação de descaso e de abandono dos moradores nos manicômios, nos quais viviam (vivem) em condições subumanas.

Em meio a um intenso debate interno nas instituições asilares, na década de oitenta, ocorreram iniciativas de humanização do hospital psiquiátrico. Conforme o Coordenador Nacional de Saúde 
Mental, Pedro Gabriel Delgado, por ocasião do I Encontro Nacional de Residenciais Terapêuticos, realizado em Paracambi-RJ no ano de 2004, consolidava-se, naquele momento histórico, “o período da reforma dos asilos, um período importante na história da reforma psiquiátrica do Brasil”. Segundo ele, apesar daquele período apresentar "poucas modificações visíveis a olho nu no sistema hospitalar", teve sua função como "escola fundamental para a formação de quadros e para o debate dos grandes impasses relacionados aos hospitais psiquiátricos”. Para ele, duas experiências marcaram o início da ideia da Residência Terapêutica. Uma, a experiência desenvolvida no Juqueri, no Hospital Franco da Rocha, que contou com a criação, nos anos 80, dos chamados "Lares Abrigados". Outra, a experiência de Barbacena com a construção de casas no espaço asilar, que, mesmo localizadas sob o "manto protetor da instituição", objetivavam a autonomia dos usuários e a melhoria da qualidade de vida dos mesmos. Porém, ele ressalta que, naquele momento, o desafio de humanização e democratização do asilo não dispunha de "uma construção teórica de como iríamos, de fato, conseguir atender a todas essas pessoas quando elas começassem a sair dos hospitais, quando nós começássemos a fazer com que elas saíssem dos hospitais".

O II Congresso Brasileiro de Saúde Mental, realizado na cidade de Bauru - SP, em 1987, constituiu-se em um marco para tais discussões, contando com a participação de diferentes segmentos sociais: entidades e categorias profissionais, familiares e usuários. Fundou-se, naquela ocasião, o denominado Movimento da Luta Antimanicomial, com o lema "Por uma Sociedade sem Manicômios", desenvolvendo uma crítica radical aos hospitais psiquiátricos.

No mesmo período, importantes movimentos no campo da Saúde Pública aconteciam no país. A $8^{a}$ Conferência Nacional de Saúde, realizada, em 1986, em Brasília, teve como fundamento a proposta da Reforma Sanitária. Posteriormente, foi aprovada a Lei Orgânica de Saúde $\mathrm{n}^{\circ}$. 8080/1990, construindo o Sistema Único de Saúde que tem como um de seus princípios, a universalidade do acesso, a equidade, a descentralização de recursos e a integralidade da assistência. 
A I Conferência Nacional de Saúde Mental, realizada em Brasília, em 1987, vem ao encontro dessa proposta, tendo como uma de suas principais premissas a reafirmação da Reforma Sanitária, tornado-se um marco na Reforma da Psiquiatria no Brasil. Em relação aos moradores institucionalizados, esta Conferência propõe a realização de um censo para a revisão da população de internos em hospitais psiquiátricos e a implementação de um programa de reabilitação "para esta população, partindo-se para a criação de espaços de habitação co-geridos e integrados aos espaços extra-hospitalares de atenção" (BRASIL, 1987).

Com aquele contexto político, na década de noventa, tiveram início as primeiras experiências que buscavam o "rompimento" com os muros dos hospitais psiquiátricos, através da criação de pensões protegidas e lares abrigados inseridos na comunidade.

Nesse processo de transição, a II Conferência Nacional de Saúde Mental, realizada em 1992, apontou modificações profundas no campo conceitual da Saúde Mental, reafirmando a integralidade e o trabalho intersetorial. Dessa forma, a Saúde Mental veio ao encontro da implantação do Sistema Único de Saúde, ao propor um conjunto de dispositivos sanitários e socioculturais que partem de uma visão integrada das várias dimensões do indivíduo, em diferentes e múltiplos âmbitos de intervenção (educativo, assistencial e de reabilitação). Salienta-se, assim, a necessidade das ações da Saúde Mental serem integradas a outras políticas, como de educação, cultura, esporte e lazer, seguridade social e habitação (BRASIL, 1992).

Em tal período, as pensões protegidas e os lares abrigados passaram a ser os locais para receber as pessoas oriundas dos hospitais psiquiátricos, aliando-se a ideia da criação de centros de convivências, como espaços de encontro com a cidade.

Segundo Juarez Furtado (2006), os municípios de Porto Alegre (RS), Campinas (SP), Santos (SP), Ribeirão Preto (SP) e Rio de 
Janeiro (RJ) foram pioneiros nessas experiências, gerando subsídios importantes para que tais iniciativas viessem a ser incorporadas como política do SUS, a partir da publicação da Portaria MS 106/2000, que criou os Serviços Residenciais Terapêuticos.

Esses movimentos desencadearam a aprovação, em 2001, da Lei Federal N 10.216 da Reforma Psiquiátrica, após 12 anos de tramitação até sua aprovação no Senado Federal. A Lei dispõe, em seus artigos, sobre a regulamentação dos direitos do portador de transtornos mentais, vetando a sua internação em instituições psiquiátricas com características asilares. Propõe para os pacientes egressos das instituições psiquiátricas uma

política específica de alta planejada e reabilitação psicossocial assistida, sob responsabilidade da autoridade sanitária competente e supervisão de instância a ser definida pelo Poder Executivo, assegurada a continuidade do tratamento, quando necessário (BRASIL, 2004).

A aprovação da Lei da Reforma Psiquiátrica foi fundamental na "legitimação" dos serviços substitutivos existentes no país. Estes serviços, por não contarem com esse dispositivo legal, encontravam-se, em alguns momentos, em situação desfavorável e frágil perante as diferentes instituições que contribuíram para a exclusão da loucura.

A III Conferência Nacional de Saúde Mental, realizada em dezembro de 2001, propôs a regulamentação imediata da Lei 10.216/01, com o objetivo de garantir a assistência ao portador de transtornos mentais em serviços abertos, prescindindo dessa forma da internação nos hospitais psiquiátricos e definindo as "unidades tipo CAPS como referência local, microrregional e regional local para assistência em Saúde Mental" (BRASIL, 2001). Nesta Conferência, deliberou-se, ainda, sobre o "destino" dos egressos do sistema asilar, que passaram a ter como referência, não mais os chamados Lares Abrigados e Pensões Protegidas, mas os denominados SRTs. 
A Portaria MS 106/2000, no Artigo $1^{\circ}$, dispõe sobre os SRTs

como moradias ou casas inseridas, preferencialmente, na comunidade, destinadas a cuidar dos portadores de transtornos mentais, egressos de internações psiquiátricas de longa permanência, que não possuam suporte social e laços familiares que viabilizem sua inserção social (BRASIL, 2004).

A criação dos Serviços Residenciais Terapêuticos, no entanto, gerou uma imensa gama de questionamentos no que se refere à forma tanto dos cuidados nesses espaços como dos usuários suprirem suas necessidades diárias de alimentação, vestuário, lazer...

Em 2003, foi votada a Lei 10708 denominada De Volta para Casa, que cria o auxílio Reabilitação Psicossocial para as pessoas que ingressam nos SRTs ou retornam para suas famílias. Esse auxílio ampliou o poder contratual dos usuários, através da viabilização de abertura de conta bancária e da aquisição de cartão em seu nome para a retirada do benefício.

Alguns dos deslocamentos, operados nesse acesso e nas possibilidades de mudança no posicionamento atribuído ao portador de sofrimento psíquico, podem ser percebidos em falas como as de Líria. Esta, moradora de um Residencial Terapêutico da região Sul do país, ao referir-se ao Programa de Volta para Casa, coloca: "Eu não sou mental. Tenho cartão do banco!” (FRICHEMBRUDER, 2003). A moradora, ao situar-se como "não mental", contrapunha-se ao discurso da loucura enquanto doença mental e trazia o cartão de banco como uma marca significativa do seu "novo" lugar na cidade.

O gerente do banco, ao falar do Programa e de como foi se dando sua relação com os usuários na instituição bancária, trouxe um outro olhar ao dizer: 
Eventualmente um ou outro não veio com cartão, esqueceu o cartão, não lembra o número da conta. Mas este é o nosso dia-a-dia. Não são eles, não é uma exclusividade deles. Muitos clientes nos solicitam esta informação no nosso dia-a-dia, então não há diferença nenhuma. Eu sinto que eles se sentem cidadãos. A partir do momento que eles têm uma conta bancária, eles se sentem realmente pessoas atuantes, inclusas na sociedade (FRICHEMBRUDER, 2003).

Embora possamos problematizar a noção de cidadania vinculada a uma conta bancária e a finalidade de tornar o máximo de pessoas integradas e produtivas ao sistema econômico-político nas sociedades capitalistas, não podemos negar que, nos dias de hoje, na sociedade de consumo, as identidades e o sentimento de pertencer a determinados grupos sociais encontram-se marcados por ter ou não conta em banco e cartões de crédito.

O fato de ter uma conta bancária e ser dono de um cartão, de certo modo gerou novas configurações nas relações de tutela em funcionamento entre os cuidadores e usuários. Para ilustrar vejamos, como exemplo, a estratégia adotada pelos profissionais para o controle dos gastos dos usuários, através do recolhimento dos seus cartões, e como um usuário buscou garantir o recebimento e o uso de seu benefício. Paulo, inconformado com a retirada de seu cartão por sua cuidadora, que não aceitou o modo como ele usou seu benefício - gastou tudo no mesmo dia em que recebeu -, dirigiu-se ao gerente da sua conta. Apresentou-se como beneficiário do Programa e solicitou o recebimento do mesmo sem a documentação necessária para a realização de retiradas bancárias. O gerente, diante dos argumentos utilizados pelo "titular da conta", autorizou a transação bancária, atendendo a demanda do beneficiário.

Os exemplos citados trazem alguns elementos para pensarmos, o reconhecimento da "fala do louco" secularmente emudecida pelos muros do manicômio. A possibilidade de Paulo ser reconhecido em 
outro lugar, de forma semelhante à interpretação de Líria sobre si, ao intitular-se como "Não Mental" por ter um cartão bancário. Ao mesmo tempo, deparamo-nos com o controle dos profissionais ao retirarem do usuário o direito de utilizar o seu benefício, de cometer erros no orçamento, comuns na vida de outros habitantes da cidade, que driblam suas falhas na administração das finanças, através de contas com limite que cobrem e encobrem os seus gastos. Essas cenas, das vivências desses "novos" habitantes da cidade, trazem fragmentos de situações marcadas por "lutas" diante das possibilidades que vão sendo criadas para a vida dos usuários, conflitos gerados entre as ações dos cuidadores direcionadas ao controle das condutas dos usuários e os seus comportamentos de resistência, ao posicionarem-se seja como "não mental" seja como um "cliente bancário" de direitos.

Na próxima seção, apresento diferentes percursos e interstícios dos (Des)Encontros da Loucura com a Cidade, na criação de possíveis "desenhos" do mapa da Reforma Brasileira. Para tanto, trago narrativas tecidas no convívio das pessoas (cuidadores, usuários e vizinhos) nos Residenciais e na cidade, buscando mostrar outras tramas construtoras de (im)possibilidades de vida, já que "as linhas do enredo diferente das quais as pessoas participam as constroem de modo diverso" (LOPES, 2001).

\section{"Esta casa, não é a minha casa"! Os Residenciais e sua inserção Sistema Único de Saúde: Labirintos que se Entrecruzam}

Samuel, morador de um Residencial Terapêutico, na região Centro-Oeste do país, durante uma de nossas conversas junto com os demais moradores de sua residência, comenta: "Esta casa, não é a minha casa!". A escuta dessa fala, naquela manhã, causou-me perplexidade e tristeza. Esses sentimentos - gerados, talvez, pela 
minha trajetória e militância na Saúde Mental e pelo afeto que passei a sentir no convívio com aqueles moradores - "impediram-me" de retornar para o Residencial, no período da tarde, conforme havia programado. A sensação de impotência diante de seu descontentamento, levou-me a pensar: O que levaria Samuel a não sentir aquela casa como sua?

Esta pergunta reportou-me às contribuições de Benedetto Sarraceno (1999) que nos aponta para a necessidade de estabelecermos um diferencial entre "estar" e "habitar" e de olharmos para as relações de poder que se estabelecem no morar. Segundo o autor, "o estar tem a ver com uma escassa ou nula propriedade (não só material) do espaço por parte do indivíduo, com uma anomia ou anonimato do espaço em relação à organização material e simbólica", enquanto o habitar "tem a ver com um grau sempre mais evoluído de propriedade (não só material) do espaço no qual se vive”. Todavia, ele ressalta que, mesmo nas nossas casas, podemos ter uma perda do poder contratual, material e simbólico, experimentando um aprisionamento no habitar (CAMARGO JÚNIOR, 2004).

Ao chamar a atenção para o aprisionamento do habitar, mesmo nas nossas casas, Sarraceno leva-nos a pensar sobre a complexidade do "habitar um serviço", vivendo sob o "olhar" e as diretrizes do Sistema Único de Saúde. Para pensarmos na abrangência dessa questão e nos possíveis interstícios do morar em um Residencial, talvez sejam úteis as contribuições de Juarez Furtado (FURTADO, 2006). Ao analisar a portaria que institui os Serviços Residenciais Terapêuticos, Furtado refere que esta é "freqüentemente questionada por diversas razões [...] Sobretudo a palavra 'serviço' acaba levando erroneamente, a idéia de alguma similaridade com centros de saúde, clínica”, etc. (FURTADO, 2006), mas assim estabelecida para justificar sua inserção no Sistema Único de Saúde (SUS).

A inserção dessas moradias no SUS, como forma de garantia do financiamento para a Saúde Mental, insere em um Ministério (no 
caso o da Saúde) dois direitos do cidadão, Saúde e Habitação, através de uma única política pública.

Outro aspecto das diretrizes do Sistema Único de Saúde a ser repensado refere-se à definição de integralidade nos cuidados. A esse respeito Kenneth Rochel de Camargo Júnior (2004) alerta para o expansionismo semântico a que a integralidade está sujeita. $\mathrm{O}$ autor questiona "se é possível, ou mesmo desejável", um tipo de atenção que se dirija à "totalidade das necessidades de um ser humano", apontando como contrapartida desta expansão "o risco de um grau de controle sem precedentes, de perda de autonomia, uma medicalização também integral”.

Os comentários de Samuel, morador em um Residencial, em uma de nossas conversas com seus amigos sobre o cotidiano de suas vidas, trazem elementos que nos fazem interrogar sobre os riscos do expansionismo da atenção. Ao falar sobre o livro para "passagem de turno" utilizado pelos cuidadores do Residencial, ele diz: "Antes quem regia as nossas vidas era o hospital psiquiátrico, agora quem rege as nossas vidas é a Secretaria de Saúde!”.

Ao nos reportarmos às considerações de Camargo Júnior (2004) sobre a "indefinição de integralidade" e aos comentários de Samuel sobre o morar naquele Residencial, vemos como vital, nesse processo, estarmos atentos ao que o autor chama de "imperialismo sanitário". Pois, possivelmente, o sentimento de "não pertencimento" de Samuel ao Residencial onde vive e a afirmação de que sua vida é "regida pela Secretaria de Saúde" estejam permeados por este "açambarcamento de toda experiência humana sobre a rubrica da saúde” (CAMARGO JÚNIOR, 2004).

Foucault (1986), ao discutir os movimentos precursores da Reforma Psiquiátrica, refere que "as relações de poder constituíam o a priori da prática psiquiátrica”. Em suas análises sobre a História da Loucura e a constituição da Psiquiatria, o filósofo nos propõe modos 
de olharmos para o funcionamento do poder nas instituições. Nesse sentido, salienta que

o essencial não é a instituição com sua regularidade, com suas regras, mas sim, precisamente, esses desequilíbrios de poder, [...]. [...] as disposições de poder, as redes, as correntes, as intermediações, os pontos de apoio que caracterizam uma forma de poder e que, creio, são precisamente constitutivos ao mesmo tempo do indivíduo e da coletividade (FOUCAULT, 2006).

A este poder, que atua no interior e através das instituições difundindo-se no campo social, Foucault (2006) denomina poder disciplinar. Uma forma de agir do poder, caracterizada por um conjunto de técnicas articuladas e direcionadas ao controle do tempo, da vida e do corpo do indivíduo.

A fala de Samuel sobre a regulação de sua vida pela Secretaria de Saúde, de certo modo, mostra o funcionamento dessa forma de poder disciplinar que o produz como sujeito, já não de uma instituição única (hospital psiquiátrico), senão de uma rede de instituições e saberes que fazem dele o "usuário" dos Residenciais terapêuticos. Parafraseando os termos da Reforma, um poder não hospitalocêntrico deve se constituir em uma imensa rede que pode ser "não substitutiva" a uma única instituição: o manicômio.

Assim, parece que precisamos olhar para a rede que produz o indivíduo e as coletividades, pois segundo Foucault, "aquilo com que se tem de lidar, antes de lidar com as instituições, são as relações de força nessas disposições táticas que perpassam as instituições" (FOUCAULT, 2006). Possivelmente, Samuel nos fala da articulação das funções institucionais com as formas táticas e estratégicas que se operam nas "teceduras" da rede hospitalocêntrica, estendendo-se e regulando a sua vida no Residencial Terapêutico na cidade. 
A respeito da relação terapêutica estabelecida nestes serviços, Maria Tavares Cavalcanti (2006), menciona que muito temos produzido em relação a chamada relação terapêutica, mas a coisa se complica quando começamos a pensar o que seria um Serviço Residencial Terapêutico: Casa ou Serviços. Se for uma casa, por que pensar em termos de uma "equipe responsável" por essa casa.

Ela destaca essa dicotomia de difícil saída a que estamos expostos, se pensarmos em uma casa tal qual conhecemos e vivemos. Ciente da impossibilidade de resolver tal impasse, Cavalcanti (2006) "propõe manter esta contradição casa/serviço viva, sem cair na contradição de resolvê-la", trabalhando nos "interstícios" desta contradição explorando ao máximo "suas diversas vertentes".

Esses (des)encontros, nesse percurso, associados a preocupação com a existência e complexidade deste morar/habitar, levaram-me a interrogar: Como seria esta casa, onde Samuel se sentisse como sendo a "sua casa"? Que morar contemplaria este habitar, dele ter um maior pertencimento a casa? Que casa seria esta para Samuel e seus amigos de Residencial?

Para ampliarmos tal discussão, lembremos que a portaria que institui os Residenciais dispõe, em seu Art. $1^{\circ}$, os Serviços Residenciais Terapêuticos como serviços destinados ao atendimento do portador de transtornos mentais. Essa função atribuída aos Residenciais, como "espaço para atendimento", me faz pensar nas possibilidades de Samuel constituir, ali, um local onde ele possa habitar no sentido proposto por Sarraceno, apropriando-se daquele espaço a ponto de percebê-lo como a sua casa.

Na busca, talvez, de um lugar para habitar e de atenuar esta "desapropriação" de seu morar, Samuel, em nosso primeiro encontro com a presença da orientadora deste projeto, dirige a ela a seguinte pergunta: "Poderias conseguir um quarto só para mim?" O morador, ao entrar na cozinha, lança esse pedido, causando-me constrangimento e impotência e, possivelmente, sensação semelhante nela, que 
respondeu: "Sou professora! Não tenho poder para isto". Sentados em torno da mesa da cozinha continuamos conversando com os moradores daquele Residencial. Contudo, a colocação de Samuel levou-me a perguntar: "Tem alguma coisa que poderia fazer vocês sentirem essa casa como sendo a sua casa?" Rosa, moradora, ali, responde: "Que cada um dormisse em um quarto e fosse dono da cama de seu quarto". À semelhança de Samuel, ela clama por um espaço seu, solicitando além do quarto, uma cama que seja a "sua cama".

Outra questão apontada pelos usuários, referente ao modo de vida nos residenciais, relacionou-se ao número de moradores nos Residenciais. Kátia, moradora de um Residencial da região sudeste, ao falar da sua experiência na primeira casa onde morou, depois de sair do hospital e das dificuldades encontradas, fez o seguinte comentário: "Seis mulheres numa casa, não têm jeito, não!".

Essas colocações trazidas pelos usuários nos remetem a pelo menos duas discussões. Uma, relacionada ao número de pessoas contempladas na Portaria dos Serviços Residências Terapêuticos, que, em seu artigo $6^{\circ}$, ao definir as características físico-funcionais dos SRTs, delibera que essas sejam compatíveis para abrigar no máximo 8 (oito) usuários. Nas regiões percorridas, observamos a tendência dos gestores de organizarem grupos de oito pessoas como forma de garantir um maior número de usuários vivendo na cidade e a consequente racionalização dos recursos do projeto. Nesta tentativa de "racionalização", encontramos a criação de moradias com quartos para três ou quatro pessoas ou, até mesmo, a prática de separação de quartos para os armários e quartos só para as camas, dificultando a possibilidade de constituir espaços individualizados.

Outro importante aspecto da vida dos moradores mencionado por eles refere-se às ações de reabilitação psicossocial, que permeiam a constituição dos Residenciais, conforme aponta Terezinha, moradora do Residencial onde vive Samuel. Na conversa sobre o morar ali, fez o seguinte comentário diante das colocações de seus amigos: "A gente não paga aluguel que está nos direitos de cada um, né! Fica 
toda a vida!”. Assim, vemos aparecer a noção de um projeto para toda vida, no qual a moradora se posiciona como "moradora eterna" do Residencial.

A fala de Samuel, sobre a "substituição" do gerenciamento de sua vida do hospital psiquiátrico para o "reger" da Secretaria de Saúde, aponta para o funcionamento, nesse modelo de atenção - "ação" pensada para a melhoria das condições de vida dos usuários e humanização do cotidiano das pessoas - de elementos sociais similares àqueles das propostas dos lares abrigadas e das pensões protegidas.

Oliveira e Conciani (2008), ao analisar a experiência de implantação dos Residenciais onde vivem Samuel, Terezinha e Rosa, destacam que:

As demandas de gestão mobilizaram de modo mais premente e todo o processo se restringiu a "construção" administrativa das residências, como locação de casas, contratação de cuidadores, garantia de alimentação, entre outros. Com uma equipe reduzida e precarizada nas condições de trabalho (grande parte contratada temporariamente) e nas relações de poder político, o processo de aprendizado técnico-político de construção desse novo dispositivo de cuidado foi praticamente ausente. (OLIVEIRA, CONCIANI, 2008).

Em relação às colocações da autora, trago um excerto de meu diário de campo, onde narro fragmentos da conversa e meus sentimentos e percepções após quatro dias de trabalho e encontros, naquele Residencial, com Samuel, Carlos, Terezinha e Rosa:

Passei cerca de quatro dias nessa casa. Fiquei mexida e triste. Eram pessoas muito jovens e lúcidas; lúcidas dessa maquiagem da Reforma... Samuel diz em nosso bate-papo: 
"Agora quem rege nossas vidas é a Secretaria de Saúde!" Carlos comenta: "Antes os documentos estavam no hospital psiquiátrico. Perderam! Agora fizeram os novos e eles estão na Secretaria." Samuel, coloca de forma clara: "Esta casa, não é a minha casa!" Passei por uma situação de constrangimento, pois todos se apresentavam como sendo aposentados e os gestores falaram-me que os moradores não precisavam de mais dinheiro, por isso não pediram o LOAS para ninguém! Então, como eram aposentados? Falei então do De Volta para Casa. Terezinha ficou feliz e perguntou-me: "O que? Tu vais nos levar para a casa?" Foi horrível, pois se encheu de esperança "apostando" que estava ali para levá-la para casa! Tentei explicar o que era o De Volta para Casa. Eles não sabiam do que se tratava. Continuaram dizendo que estavam aposentados, sem serem aposentados legalmente. Fiquei mal. Não consegui voltar à tarde para o Residencial (FRICHEMBRUDER, 2003).

Nessas conversas, tornou-se visível a falta de perspectiva na vida daquelas pessoas, de ter um sonho, ou simplesmente, uma cama sua, um quarto. Ao mesmo tempo, percebi, com certa lucidez, os meandros da Reforma Psiquiátrica em curso, quanto o gerenciamento do tempo daquelas vidas e corpos através das ações da Secretaria de Saúde, delineando fragmentos do "Mapa da Reforma", borrados de figuras e formas similares à vida no hospital psiquiátrico. Vidas de pessoas que se encontram e convivem num "sobradinho verde, muito bonito", conforme anoto em meu diário de campo.

"Sobradinho verde, muito bonito", mas com histórias de pessoas que, diferentes de Líria que se posicionou como "não mental" ao ter um cartão bancário do benefício De Volta para Casa, foram "aposentadas" pelos gestores ao receberem o mesmo programa, cujo 
auxílio visa a reabilitação psicossocial e não o posicionamento dessas pessoas como inaptas para o trabalho.

No curso das visitas aos Residenciais, ao compartilhar de momentos de refeições, vi-me na presença de utensílios que, de certo modo, falam dos lugares e dos olhares instituídos para essas pessoas. Como descrevo num fragmento do diário de campo: "Nessa casa vi as tais canecas azuis que tinham no hospital onde trabalhei no Sul, e também onde pesquisei no Nordeste, agora estavam ali nos Residências do Centro-Oeste”.

Num outro dia, ao conversar com Fabiana, uma amiga e cuidadora dos SRTs do Sul, comentei sobre o uso das canecas de plástico nas regiões onde eu havia estado. Diante de minha observação, ela comenta parecendo estar intimidada: "Engraçado! Volta e meia, aparecem canecas azuis na casa onde sou acompanhante. Não sei de onde elas vêm, mas trato de botar elas fora!" A sua cumplicidade e desconforto diante das canecas azuis de plástico me confortavam. Contudo, intrigava-me a dimensão da irritação gerada pela presença desses utensílios nos SRTs. Mas, por que trazer as canecas azuis para o diário de campo, para as conversas com os amigos e para a discussão de um artigo?

Nas discussões que faz sobre a posição do narrador, Jeanne Marie Gagnebin (2004)1 assinala que o narrador é uma espécie de "sucateiro", isto é, aquele que traz os restos, esse personagem encarregado de pegar aquilo que parece sem significado e fora da história oficial, mas que carrega consigo marcas, memórias e experiências. Assim, no percurso de narradora e de desenhar o mapa de (Des) Encontros da Loucura com a Cidade, penso e vejo nessas canecas/ sucatas uma permanência silenciada, cuja forte presença, até hoje, carrega marcas dos modos como se pensou e agiu com relação à "loucura" no Brasil.

1 Segundo as análises de Walter Benjamin (1994), no seu texto intitulado O narrador, considerações sobre a obra de Nikolai Leskov. 
Ao encontrar, novamente, tais sucatas, em outras regiões percorridas pelo país, pensava que deveria tê-las fotografado como "prova" de minha visão. Mas o que queria provar? O uso das canecas azuis, em substituição aos copos de vidro, possivelmente, fala de um cuidado com o corte, de um possível corte a ser evitado com o uso de canecas inquebráveis; de um "possível lance" de "possíveis agressores" no convívio na casa instituída para prestar atendimento ao portador de transtornos mentais, conforme referenda a Portaria.

Essa presença, nas casas, conta de um olhar invisível e vigilante que vigia "sem estar presente, já que a vigilância poderá ser mais que virtual" (FOUCAULT, 2006). Um olhar sutil do poder disciplinar que controla e ordena os acontecimentos nos espaços, da casa onde habitam ou na hora de saciar a sede, quando ao lembrar: Cuidado, você pode se tornar perigoso! Segundo Foucault (2002b) o conceito de periculosidade da loucura dá-se pelo intercruzamento do diálogo entre o direito penal e a necessidade de respaldo da medicina higienista para afirmação da Psiquiatria enquanto ciência médica.

No entanto, Foucault chama nossa atenção para o fato de que essa noção não está centrada somente na Medicina ou no Direito, mas "são todas as disciplinazinhas da escola, da caserna, do reformatório, da usina, que tomam cada vez mais espaço. Todas essas instituições proliferando, estendendo-se, ramificando suas redes em toda a sociedade" (FOUCAULT, 1999). Ramificações que me parecem brotar, naquilo que vivenciei, como "ervas daninhas" nos espaços onde vivem os ex-moradores dos hospitais psiquiátricos.

Esses achados no mapeamento da desinstitucionalização no país fazem-me pensar em Fra Mauro. Este, ao compor o mapa perfeito do mundo, coloca que seu desenho, assumiu uma dimensão que não fazia parte de suas considerações iniciais, mesmo que ele pudesse presumir que estas poderiam ser, às vezes, contraditórias (COWAN, 1999). Na construção de um "mapa” da Reforma, inicialmente com traços que delineavam possibilidades de outros lugares, conquistados por Líria e Paulo na condição de clientes de um banco, 
fui percebendo modificações por lugares atribuídos à loucura, mostrando-me a "terra no céu, o céu na terra" (COWAN, 1999). Percebi um mapa da Reforma Psiquiátrica Brasileira de cabeça para baixo, com posicionamentos da "loucura" relacionados à "periculosidade" e à incapacidade. Aqueles que carregam as marcas da "loucura", ao infringirem as regras que orientam as relações em diferentes domínios sociais numa certa cultura, tornam-se excluídos, não mais (ou não só) em hospitais psiquiátricos, mas, agora, nos chamados Residenciais Terapêuticos.

Neste ponto do mapa, diante daquilo que vivenciava, uma questão me assombrava, "a dúvida recorrente sobre se estava conseguindo obter uma visão correta do mundo" (COWAN, 1999). Porém, o problema não é se essa visão que trago é correta ou não, visto que um olhar, ao ocorrer numa certa direção mostra um recorte, um olhar em perspectiva que, ao conhecer, desconhece tantos outros ângulos possíveis de ver e pensar o que chamei de (Des)Encontros da Loucura com a Cidade. Assim, neste mapeamento, em certa medida panorâmico, trago, a seguir alguns fragmentos de minha experiência na região Sudeste do Brasil, onde emergiram elementos para pensarmos outras relações possíveis no cotidiano dos moradores e dos gestores dos Residenciais Terapêuticos.

\section{"Eu Vim para Casa e o Hospital Psiquiátrico ficou lá": A Casa das Xícaras de Porcelana}

"As águas de março" banhavam as extensas margens dos rios, em minha passagem por uma cidade do interior no Sudeste do país, no final do verão. O inverno dava seus primeiros sinais de futura chegada e as vestimentas trazidas de minha viagem pelo Norte do país não davam conta do vento frio que batia nos meus pés. Comprar sapatos para "portador" de pés grandes, nessa cidade, era inviável, pois as pessoas na média tinham estatura mais baixa ou pés menores. Eu "fugia” da norma, naquele lugar "de sapatos e pés 
pequenos”. O jeito era caminhar mais rápido para atenuar o frio, dar uma parada para tomar um café quente ou pegar um táxi, tentando burlar o vento frio que chegava de mansinho.

Numa dessas tentativas de fugir do desconforto, aceno para um taxista desta "estranha" cidade sem semáforos nas ruas. Um senhor moreno e estatura baixa abre a porta de seu veículo, recebendo-me de forma amistosa. Peço, então, para que me leve para a Rua da Cartomante. Francisco, o taxista, roda pela cidade, em busca dessa estranha rua que eu apresentava para ele, no trabalho de campo que realizava em sua cidade.

Num certo momento, virando à direita, chegamos a tal da "Rua da Cartomante". Ao confrontar o número do Residencial com a localização que eu recebera, aviso ao taxista que estávamos em frente à casa que buscava. Francisco, então, com certa incomodação me pergunta: "Por que a senhora não me disse que iria num SRT? Se a senhora pedisse pelo SRT, eu lhe traria direto".

A pergunta de Francisco era inesperada naquele "ponto" do mapa? O lugar do Residencial na cidade, para "além dos muros do manicômio" alinhavava os borrões do "Mapa da Reforma" de uma outra forma.

As moradoras daquela casa, Marilda e sua amiga Kátia eram clientes de Francisco. Sem perceber, eu já havia entrado em "seu Residencial” antes mesmo de encontrá-las. Francisco já as apresentava como "boas negociantes", contando-me que existe uma combinação entre eles, delas pagarem somente a ida do percurso em um chamado, se a volta para casa se der em um pequeno espaço de tempo.

Ao descer do táxi, gritos, vindo da casa, interrompiam meu impulso de chegar até o portão. Eles contrastavam com os "gritos dos loucos", moradores das instituições psiquiátricas. Eram "gritos de caturritas", que, além de sinalizarem a minha aproximação daquela morada, anunciavam a presença de vida naquela casa. 
Ao entrar, depois de receber as boas-vindas de Kátia e Marilda, uma imagem causou-me impacto no encontro com elas. As paredes rosa-claro da sala, cobertas até o teto por pratos e xícaras de porcelana, que, também, cobriam o rack do aparelho de som, a mesa de aproximação e o balcão da sala. As louças de porcelana eram destacadas por duas exuberantes samambaias da Amazônia e outras lindas plantas, que ora disputavam o "papel principal" ora compunham um cenário de indefinível beleza.

O encantamento pelos ornamentos de vidro e pela composição, naquele momento, acalentou o meu desconforto na presença das canecas de plásticos em diferentes pontos do país. A fragilidade desses utensílios mostrava-me um cenário diferente da Reforma, visto que com um simples toque tais objetos poderiam se desintegrar, machucar o seu portador ou outra pessoa. Numa perspectiva de exclusão, representariam um risco num local para atendimento, mas, neste Residencial, estavam como ornamentos e objetos colecionados por Marilda.

À semelhança de Fabiana (cuidadora e amiga com quem conversara sobre as canecas azuis), possivelmente Marilda, afinada com aqueles gestores do Projeto, não "admitia" canecas de plástico como anúncio da "periculosidade dos loucos”, e em seu lugar, xícaras de porcelana "revestiam" os móveis e as paredes da casa, impedindo brotar, ali, aquelas "ervas daninhas".

Essa cena me traz à lembrança a conversa que tive com a gerente administrativa de uma das "casas com canecas de plástico". Ao perguntar-lhe por que não constavam, em suas listas de compras, copos de vidro e facas, fui surpreendida com uma outra pergunta: "Como vou dar facas e copos para quem viveu em hospitais psiquiátricos?”

Marilda, colecionadora das xícaras porcelana, ao receber meus elogios sobre a beleza de seus objetos, de sua composição com as samambaias exuberantes, respondeu-me orgulhosa: "Eu vim para casa e o hospital psiquiátrico ficou lá!”. 
Ao passar pela sala de estar, fui encaminhada à sala de jantar. Nela, as moradoras mostraram-me seus objetos e móveis, que foram substituindo aqueles adquiridos pela Secretaria de Saúde e pela ONG, parceira na administração do Projeto daquela cidade.

No percurso de minha visita pela casa de Kátia e Marilda, vou sendo encaminhada à área de serviço. Acima de uma das portas, encontro as anunciantes da minha chegada, as caturritas: Kika e Coca! Ao direcionar a máquina fotográfica para elas, Kika põe-se a frente da gaiola e arrepia suas penas, exibindo-se com sua plumagem.

De volta para os aposentos da casa, Marilda abre um dos quartos que estava com a porta fechada. Ao abrir, dá triste notícia que Sueli, a dona daquele quarto e sua amiga, falecera. Conta-me que, após sua morte, elas transformaram o quarto em uma sala de televisão, colocando um sofá vermelho com almofadas onde Nina, a gata da casa, passou a dormir. As amigas falam da falta de Sueli, da torta que compraram para ela um dia antes dela falecer, pois Sueli "adorava doces”. Contam-me, também, um dos pedidos que ela fez antes de morrer, que Marilda "não brigue” mais com Kátia.

Em função da morte de Sueli, os gestores apontaram a possibilidade de outra pessoa vir morar com elas, e ambas pediram para continuar morando "sozinhas" naquela casa. A esse pedido, receberam a contraproposta de passarem a pagar suas despesas de alimentação, até então pagas pela prefeitura e pela ONG, e foram chamadas para discutir a situação apresentada com ambos os gestores.

A condição posta pelos gestores provocou certa revolta em Kátia e Marilda, por acharem que deveriam continuar "recebendo tudo", utilizando seus benefícios apenas para a compra de roupas e o lazer. Enquanto Marilda, mesmo inconformada com as novas exigências, expressa com palavras a importância deste momento em que passam a financiar a sua alimentação, Kátia demonstrou inconformidade total com a proposta. 
Esta casa, com seus objetos, móveis, contas para pagar, bichos de estimação, amigos na cidade, parece criar condições para o habitar de suas moradoras, em contraste ao "morar" abordado anteriormente.

Esses encontros naquela cidade, com o taxista, a vizinhança da Rua da Cartomante, lugar ocupado por Marilda, ao "colocar as cartas" para suas amigas do bairro, apontam possibilidades de dar existência para outros olhares e lugares no "entorno" e no espaço do Residencial.

Num outro momento, em uma entrevista com Lúcia, uma das gestoras do Projeto desde o início de sua implantação naquela cidade, sobre aquela casa, ela me contou que esse habitar foi se configurando num processo de "diluição" da experiência inicial de criação do primeiro Residencial. Segundo Lúcia, aquela experiência ocorria dentro de uma lógica hospitalar, com a presença de um médico e uma psicóloga no interior da casa. Ela conta que foi muito trabalhosa esta primeira casa, as pessoas não sabiam como fazer. Ao falar sobre essa primeira experiência, que "resultou" na constituição da casa onde vivem, hoje, Marilda e Kátia, Lúcia conta:

A casa hoje tá completamente diluída nas outras, até mesmo porque isso tinha relação de poder, que de modo é complicado [...], entendeu? Ela (referindo-se a Marilda) exercia um poder de dona da casa, [...] e que tem que tá atento a isso, [...]. Ninguém agüentaria ficar o resto da vida com ela, porque ela não é fácil né? Agora ela deu uma acalmada, ela chegou, acho que ela queria, a companheira que ela queria para morar é essa, o perfil é o da Kátia (FRICHEMBRUDER, 2003).

Retornando à conversa com as moradoras sobre o morar num Residencial, Marilda contou-me que uma dificuldade, no início, foi a presença de Ana: "que ficava jogando o remédio fora e ela 
ficava chorando o tempo todo". Kátia lembrou de uma outra moradora, que deixava o banheiro sem condições de uso, com fezes no entorno do vaso sanitário, o que tornava impossível receber visitas. Ela menciona, também, problemas gerados pelo número de pessoas morando numa mesma casa. Essas dificuldades levaram Marilda e Kátia a solicitar morarem juntas em uma casa diferente da de Rita. Esta, segundo seu desejo, passaria a morar sozinha. Diante disso, os gestores concordaram em alugar um outro imóvel para as amigas e uma casa para Rita morar sozinha. Possivelmente, essa primeira experiência de Marilda, Kátia, Sueli e Rita as moveria na direção de dizer, assim como Samuel, "Esta Casa, não é a minha casa!"

Dentre as peculiaridades dessas experiências nos Residenciais, onde vivem Samuel e Marilda, pode-se dizer que se diferenciam as relações com os gestores dos Projetos. No primeiro caso, do morador Samuel, os gestores construíram uma visão exitosa, não problemática daquela experiência. No segundo caso, os gestores olham a experiência numa perspectiva problematizadora que tenciona as situações vividas e usa os "erros" e as dificuldades para mobilizar o pensamento na direção de novas possibilidades no enfrentamento dos conflitos. Esse modo de lidar com os acontecimentos cotidianos torna-se visível na fala de Lúcia:

Então assim, tem erros, acho que tem erros, acertos e a gente vai, do modo como aparece um problema, tenta achar uma solução pra ele, tenta fazer com que isso seja novo pra todo o funcionamento, mas às vezes demora pra acontecer! Você às vezes dá conta: ó nós estamos errando ali, pode melhorar isso aqui, sabe?

Com essa atitude inventiva de "soluções" engendradas nos problemas cotidianos, tais gestores poderiam ser descritos por suas posturas de atenção e de escuta às demandas dos usuários, 
que desacomodam e colocam à prova as "verdades" e as "certezas" adquiridas no saber especializado sobre o modo de agir num serviço, mesmo residencial, ligado ao campo da Saúde. Em lugar do saber dos especialistas, pareceu-me que, ali, vão se configurando saberes e ações ligadas às existências individuais e coletivas, que vão diluindo projetos iniciais, como a "primeira casa", e abrindo possibilidades para moradias que "colocam em suspenso" o morar, num Serviço de Saúde, referendado na portaria ministerial.

Assim, esses tracejos do mapa da Reforma em diferentes pontos do país, mais do que apontar para a necessidade de revisão da Portaria Ministerial, que delibera sobre os SRTs, de modo que se criem condições para ações interministeriais, por exemplo através de políticas habitacionais, e para a diluição de intervenções fundadas, ainda, num possível "imperialismo sanitário", mostram a urgência de se atentar e rever a forma como os ex-moradores de hospitais psiquiátricos estão sendo vistos ao ingressarem e viverem nos Residenciais.

Para além de um dispositivo legal, a existência nos Residenciais, cabe-nos uma atitude atenta ao olhar e ao posicionamento atribuído à "loucura", em espaços criados não apenas para "substituir" o manicômio, mas sim para desenvolver uma outra forma de nos relacionarmos com estes outros diferentes, que chamamos de loucos. Lugares, onde se poderia dar passagem a outros modos de viver, diferindo, por exemplo, do "cultivo (in)discriminado" das canecas de plástico, como forma de "proteção" de seus habitantes e "cuidadores". Modos de viver, que não esboçassem, nas "entrelinhas”, a periculosidade e a incapacidade dessas pessoas gerirem suas vidas, agora, nos Residenciais.

Finalmente, o que nos incita a esse pensar sobre a loucura? Com a intenção de deixar espaço para outros tracejos, para além dos realizados aqui, nesse mapeamento inicial dos modos como nos relacionamos com as pessoas que vivem, hoje, nos Residenciais, 
trazemos as palavras de Foucault, que nos convidam a um encontro diferente com isso que chamamos de doença mental:

Saberemos apenas que nós outros, ocidentais idosos de cinco séculos, fomos sobre a superfície da terra essas pessoas que, dentre outros traços fundamentais, tiveram este, o mais estranho de todos: mantivemos com a doença mental uma relação profunda, patética, difícil talvez de formular para nós mesmos, mas impenetrável a qualquer outra, e na qual experimentamos o mais vivo de nossos perigos, e, talvez, nossa verdade mais próxima (FOUCAULT, 2002a).

\section{Referências}

ALVES, D. S.; GULJOR, A. P. O Cuidado em Saúde Mental. In: PINHEIRO, R.; MATTOS, R. A. Cuidado: as fronteiras da integralidade. Rio de Janeiro: Hucitec, 2004.

BRASIL. Ministério da Saúde. Secretaria de Atenção em Saúde. Legislação em saúde mental: 1990-2004. 4º ed. Brasília: Ministério da Saúde, 2004.

. Ministério da Saúde. Departamento de Ações Programáticas Estratégicas. Relatório Final da $3^{\circ}$ Conferência Nacional de Saúde Mental. Brasília: Ministério da Saúde, 2001. Disponível em: <http://portal. saude.gov.br/portal/arquivos/pdf/relatorio_da_3_conferencia_de_saude_ mental.pdf $>$. Acesso em 15/06/2009.

Ministério da Saúde. Departamento de Ações

Programáticas Estratégicas. Relatório Final da $2^{\mathrm{a}}$. Conferência Nacional de Saúde Mental. Brasília: Ministério da Saúde, 1992. Disponível em: <http://portal.saude.gov.br/portal/arquivos/pdf/ 
relatorio_da_2_conferencia_de_saude_mental.pdf $>$. Acesso em $15 / 06 / 2009$.

. Ministério da Saúde. Departamento de Ações Programáticas Estratégicas. Relatório Final da $\mathbf{1}^{\mathbf{a}}$. Conferência Nacional de Saúde Mental. Brasília: Ministério da Saúde, 1987. Disponível em: <http://portal. saude.gov.br/portal/arquivos/pdf/relatorio_da_1_conferencia_de_saude_ mental.pdf. $>$. Acesso em 15/06/2009.

CAMARGO JÚNIOR, K. R. Um Ensaio sobre a (In)Definição da Integralidade. In: PINHEIRO, R.; MATTOS, R. A. Construção da Integralidade. Rio de Janeiro: Hucitec, 2004.

CAVALCANTI, M. T.; VILETTE, L. S. Casa e/ou Serviços Residenciais Terapêuticos no Contexto da Reforma Psiquiátrica Brasileira. In: FIGUEIREDO, A. C; ALBUQUERQUE, P. (Orgs.). Desinstitucionalização. A Experiência dos Serviços Residenciais Terapêuticos. Rio de Janeiro: Instituto de Psiquiatria UFRJ, 2006. p. 83-91. [Cadernos IPUB, n. 22]

COWAN J. O Sonho do Cartógrafo: meditações de Fra Mauro na corte de Veneza do século XVI. Rio de Janeiro: Rocco, 1999.

FOUCAULT, M. O poder Psiquiátrico. São Paulo: Martins Fontes, 2006.

A Loucura e a Sociedade. In: FOUCAULT, M. Ditos e Escritos I Problematização do sujeito: psicologia, psiquiatria e psicanálise. Rio de Janeiro: Forense Universitária, 2002a. p. 259-67.

. Os anormais: curso no Collège de France (1974-1975). São Paulo: Martins Fontes, 2002b.

Doença Mental e Psicologia. Rio de Janeiro: Edições Tempo Brasileiro, 2000. 
FOUCAULT, M. Problematização do sujeito: psicologia, psiquiatria e psicanálise. Rio de Janeiro: Forense Universitária, 1999.

A História da Loucura. São Paulo: Editora Universitária; 1995.

. Microfísica do Poder. Rio de Janeiro: Edição Graal, 1986.

FRICHEMBRUDER, S. C. Os (Des) Encontros da Loucura com a Cidade A Caminho de Casa: do Hospital Psiquiátrico São Pedro a um conjunto Habitacional na Zona Norte de Porto Alegre. Porto Alegre: FACED/ UFRGS, 2003.

FURTADO, J. Avaliação da Situação Atual dos Serviços Residenciais Terapêuticos no SUS: In: FIGUEIREDO, A. C.; ALBUQUERQUE, P. (Orgs.). Desinstitucionalização. A Experiência dos Serviços Residenciais Terapêuticos. Rio de Janeiro: Instituto de Psiquiatria UFRJ, 2006. p. 39-52. [Cadernos IPUB, n. 22.]

GAGNEBIN, J. M. História e Narração em Walter Benjamin. São Paulo: Perspectiva, 2004.

LOPES, L. P. M. Práticas narrativas como espaço de construção das identidades sociais: uma abordagem socioconstrucionista. In: RIBEIRO, B. T.; LIMA, C. C.; DANTAS, M. T. L. (Orgs.). Narrativa, Identidade e Clínica. Rio de Janeiro: Instituto de Psiquiatria UFRJ, 2001. p. 55-72. [Edições IPUB-CUCA]

OLIVEIRA, A. G. B.; CONCIANI, M. E. Serviços residenciais terapêuticos: novos desafios para a organização das práticas de saúde mental em Cuiabá-MT. Rev. Eletr. Enf. [Internet]. 2008; 10(1): 167-78. [Acesso em: 2009 jun. 15]. Disponível em: http://www.fen.ufg.br/revista/v10/n1/ v10n1a15.htm.

SARRACENO, B. Libertando Identidades: da reabilitação psicossocial à cidadania possível. Belo Horizonte: Te Corá Editora; 1999. 